\title{
Free as a bird? Activity patterns of albatrosses during the nonbreeding period
}

\author{
Elizabeth K. Mackley ${ }^{1,2, *}$, Richard A. Phillips ${ }^{1}$, Janet R. D. Silk ${ }^{1}$, Ewan D. Wakefield ${ }^{1}$, \\ Vsevolod Afanasyev ${ }^{1}$, James W. Fox ${ }^{1}$, Robert W. Furness ${ }^{2}$ \\ ${ }^{1}$ British Antarctic Survey, Natural Environment Research Council, High Cross, Madingley Road, Cambridge CB3 0ET, UK \\ ${ }^{2}$ Faculty of Biomedical and Life Sciences, Graham Kerr Building, University of Glasgow, Glasgow G12 8QQ, UK
}

\begin{abstract}
This is the first comprehensive study of at-sea activity patterns of albatrosses during the nonbreeding period, based on data from combination geolocator-immersion loggers deployed on the wandering albatross Diomedea exulans, black-browed albatross Thalassarche melanophris, greyheaded albatross T. chrysostoma and light-mantled albatross Phoebetria palpebrata from South Georgia $\left(54^{\circ} 00^{\prime} \mathrm{S}, 38^{\circ} 03^{\prime} \mathrm{W}\right)$. Differences in behaviour among species observed during the breeding season were maintained during the nonbreeding period, suggesting a high degree of foraging niche specialisation. Wandering albatrosses exhibited longer flight bouts, and spent more time on the water during daylight, than any of the smaller species. Light-mantled albatrosses were the most active nocturnally. During daylight, grey-headed albatrosses were the most aerial and black-browed albatrosses had the shortest flight bouts. Although all species still engaged in foraging behaviour predominantly during daylight, they spent a greater proportion of time on the water (presumably resting) during the nonbreeding period compared with the breeding period, suggesting that they could more readily meet their energy demands when no longer subject to central place constraints. There was no evidence from activity patterns that might suggest that wing feather moult handicaps flight capability during the nonbreeding period. Individuals of all species engaged in rapid east-west commutes, when considerably higher proportions of time were spent in flight than while resident, in particular during daylight, possibly because birds are unable to navigate effectively during complete darkness. Despite consistency in individual dispersal patterns, there were year-to-year differences in the nocturnal behaviour of black-browed albatrosses, probably attributable to prey variability.
\end{abstract}

KEY WORDS: Procellariiform $\cdot$ Seabird $\cdot$ Central place constraints $\cdot$ Commuting Resale or republication not permitted without written consent of the publisher

\section{INTRODUCTION}

Long-distance migration is a common trait of marine species, particularly in those exploiting seasonally productive high-latitude habitats. During winter months, these species may move vast distances to exploit more favourable feeding grounds and pursue prey, or to avoid predation, competition or seasonal deterioration in conditions (Corkeron \& Connor 1999, Kenney et al. 2001, Clarke et al. 2003, Rasmussen et al. 2007). Unlike terrestrial birds, for which there is a wealth of data on migratory behaviour (Berthold et al. 2003), much less is known about pelagic seabirds. The latter spend a high proportion of their lives at sea and most species only return to land to breed, with long intervening nonbreeding periods. As a consequence, most information on migration strategies and behaviour historically has been derived from visual observations of birds from headlands, bird-ringing recoveries and ship-based observations (Harper 1987). Although recent developments in tracking technologies have increased the available information on migration routes and distribution (Grémillet et al. 2000, Weimerskirch \& Wilson 2000, Daunt et al. 2006, Shaffer et al. 2006, Phillips et al. 2007a, 2008, Guilford et al. 2009), many aspects of seabird ecology during their migration and nonbreeding period, such as at-sea activity patterns, remain poorly understood. 
Unlike breeding birds that need to defend nest sites, incubate eggs, brood and provision chicks, nonbreeding pelagic seabirds are rarely constrained to return to colonies. Within a particular population, individuals may exhibit dispersal strategies that range from broadly resident, to partially or highly migratory (Croxall et al. 2005, Phillips et al. 2005a). These strategies reflect, for all albatrosses tracked to date, persistent individual preferences for particular ocean sectors, and consistency in the timing of major movements (Weimerskirch \& Wilson 2000, Phillips et al. 2007b). Therefore, it is probable that individuals experiencing similar foraging habitat and seasonally available prey will exhibit similar activity patterns from year to year.

Broad latitudinal sex differences in distribution occur in several of the large dimorphic albatrosses, with females tending towards tropical and subtropical waters, and males towards sub-Antarctic and Antarctic waters (Weimerskirch \& Wilson 2000, Phillips et al. 2004a). These differences may arise from competitive exclusion, niche specialisation or differences in flight performance in differing wind regimes mediated through dimorphism in mass, wing morphology and loading (Phillips et al. $2007 b)$. However, no sex differences in activity have been found for breeding birds, despite some observed discrepancies in water mass preference, and thereby available prey (Phalan et al. 2007). Although potential sex differences in moult (Weimerskirch 1991) may complicate the issue, whether a tendency for sex-related behavioural differences is found in free-ranging albatrosses, which presumably experience reduced competition, may clarify the causal mechanisms.

Albatrosses replace their wing feathers at sea during the nonbreeding period when their overall energetic expenditure and nutritional demands are lowest (Bridge 2006). However, moult may increase energy expenditure as a consequence of feather tissue synthesis, or because of reduced flight performance arising from gaps, asymmetry of wing shapes and increased wing loading (Bridge 2006). Weimerskirch \& Wilson (2000) suggested that the movements of wandering albatrosses Diomedea exulans during the nonbreeding period may be restricted because of moult, although in subsequent studies other albatrosses have proven to be highly mobile (Croxall et al. 2005). Albatrosses replace few feathers simultaneously, presumably to minimise losses in flight performance, completing complex moult patterns over successive nonbreeding periods (Prince et al. 1993, 1997).

Lack of a central place constraint may also alter activity patterns. In one of the few relevant studies of a nonbreeding procellariiform, black-browed albatrosses Thalassarche melanophris from the Falkland Islands were shown to forage year-round on the Patagonian Shelf, but nonbreeding birds had a cyclical pattern of activity over several days as they travelled between food patches, spending more time overall on the water and in longer bouts compared with during incubation (Grémillet et al. 2000). During the breeding season, the severity of the central place constraint changes with breeding stage, being weakest during incubation, greatest during brood guard and intermediate during post-guard chick rearing. Such changes in constraint are thought to have a greater influence on activity patterns than the avoidance of interspecific competition (Phalan et al. 2007). It is therefore uncertain whether inter-specific differences in activity patterns observed during breeding will be preserved during the nonbreeding period.

During the breeding period, albatrosses are able to use distinct forms of flight. Over oceanic waters far from the colony, some species, typically wandering albatrosses, make long looping search flights to locate and scavenge single, large prey such as dead or moribund squid, and spend long periods of time (bouts) on the water following prey ingestion (Croxall \& Prince 1994, Weimerskirch et al. 1997, 2005). By comparison, during area-restricted searches in regions of high prey density, typical of the Thalassarche spp., bouts of flight are much shorter and separated by relatively brief periods on the sea surface (Weimerskirch et al. 1997, Weimerskirch \& Guionnet 2002, Catry et al. 2004). The majority of prey are sought whilst flying during daylight, with some but not all species using olfactory cues (Weimerskirch et al. 1997, 2005, Fernández \& Anderson 2000, Catry et al. 2004, Nevitt et al. 2008). Nevertheless, all albatrosses studied to date (albeit some more than others) exhibit some nocturnal feeding activity, in particular the Phoebetria spp., which are most aerial (Phillips et al. 2005b, Phalan et al. 2007). Other species typically use an opportunistic sit-andwait strategy, thought to be adapted to the capture of bioluminescent prey that migrate to the water's surface at night (Fernández \& Anderson 2000, Catry et al. 2004, Weimerskirch et al. 2005). Although few studies have combined devices that monitor both activity and prey consumption (Catry et al. 2004, Weimerskirch et al. 2005), these studies have, nevertheless, shown that activity patterns may be used to infer foraging behaviour and prey selection.

The aims of the present study, which is the first detailed study of the at-sea activity patterns of 4 albatross species during the nonbreeding period, are to test whether: (1) differences exist in activity patterns of sympatric albatrosses away from the breeding colony, (2) differences in species behaviour recorded during breeding persist in the nonbreeding period and (3) individual behaviour is consistent or flexible by comparing nonbreeding behaviour across years and during resident and commuting periods. 


\section{MATERIALS AND METHODS}

Combined geolocator-immersion data loggers (Afanasyev 2004) were deployed on adult black-browed albatrosses, grey-headed albatrosses Thalassarche chrysostoma, light-mantled albatrosses Phoebetria palpebrata and wandering albatrosses caught at their nests on Bird Island, South Georgia (54 00' S, $\left.38^{\circ} 03^{\prime} \mathrm{W}\right)$. Activity and geolocation data were available for 25 black-browed albatrosses (24 of which were tracked in 2 consecutive nonbreeding periods, 2002 and 2003, and one was tracked only in 2002), 8 grey-headed albatrosses (3 deployments in 2003 and 5 in 2006), 18 wandering albatrosses (all deployments in 2003) and 11 light-mantled albatrosses (1 deployment in 2003 and 10 in 2004). Data loggers were retrieved during the following breeding seasons. With the exception of the black-browed albatrosses, data from only one (the first) nonbreeding period (from colony departure to first return including intervening summers) were included in analyses, median durations of which were 6 mo (black-browed albatross), 8 mo (grey-headed and lightmantled albatrosses) and 12 mo (wandering albatross). All 8 grey-headed albatross deployments were on failed breeders. Wandering albatrosses were sexed by size and plumage, and black-browed albatrosses by either their behaviour (copulatory position) or molecular sexing (see Phalan et al. 2007). The sex of grey-headed and lightmantled albatrosses was unknown.

The data loggers, which weighed $9 \mathrm{~g}$, were attached to a plastic ring fitted around the bird's tarsus. This load $(<0.4 \%$ of adult body mass) was far less than that (ca. $3 \%$ ) at which effects on bird behaviour may become apparent (Phillips et al. 2003). The loggers measured visible light intensity every minute, and tested for saltwater immersion every $3 \mathrm{~s}$, storing the maximum (truncated) light level, and sum of positive tests (between 0 and 200, such that a value of 0 indicates the logger was always dry, and 200 indicates that the logger was always wet) at the end of each $10 \mathrm{~min}$ block. The light data were processed using MultiTrace (Jensen Software Systems) (see Phillips et al. 2004b). Briefly, the timing of sunrise and sunset was determined from thresholds in light curves; latitude was derived from daylight length and longitude from the timing of local midday with respect to Greenwich Mean Time and day of the year. Locations derived from light curves with obvious interruptions around dawn or dusk were excluded from the analysis. A speed filter was used to highlight sustained easterly $\left(20 \mathrm{~km} \mathrm{~h}^{-1}\right)$ or westerly $\left(12 \mathrm{~km} \mathrm{~h}^{-1}\right)$ changes in location, with appropriateness of these speed thresholds and designation of sustained periods of transit determined by visual inspection before the analysis of activity data. This procedure could be carried out on longitudes even if latitudes were unavailable during equinox periods (when day length is similar throughout the globe). Consecutive days of rapid transit were designated as commuting periods; otherwise, birds were considered to be resident.

The activity data were processed automatically using scripts written in R2.8.0 (R Development Core Team 2008). Each 10 min block was categorised as daylight or darkness, based on the timing of nautical twilight (derived by analysis of the light curves in MultiTrace). Five measures of activity were calculated: the percentage of time spent on the water in both darkness and daylight, the percentage of the total time spent on the water in each day (consecutive light and dark period) that occurred during darkness, and the length of flight bouts in minutes during both darkness and daylight. Although the loggers integrated activity within each 10 min block and so did not provide the exact timing of landings and take-offs, Phalan et al. (2007) found for comparative purposes that bouts, defined as a continuous sequence of 0 values for flight (dry) and a sequence of values of 1 or greater for wet bouts, were suitable proxies for activity. To test whether commuting phases coincided with moonlit nights, the illuminated proportions of the moon's visible disk at noon (universal time) were obtained from the Astronomical Applications Department of the US Naval Observatory (aa.usno.navy.mil/data/docs/ MoonFraction.html).

To increase the normality of data distributions, flight bout durations (min) were double-log (base 2) transformed, and proportion data were arcsine transformed. Because activity data are inherently pseudo-replicative, the activity measures were either averaged by individual bird and then compared by means of conventional parametric tests (ANOVA and $t$-test), or used to fit mixed-effect models in which 'individual bird' was treated as a random effect (Pinheiro \& Bates 2000). One-way ANOVA were used to compare individual and intra-specific variability in activity patterns. The effects of species and sex were modelled separately with mixed-effects generalised linear models fitted by penalised quasi likelihood, with binomial errors (Venables \& Ripley 2002). Year was included in the initial species model to allow for different deployment dates, but was nonsignificant and removed during subsequent model selection. Within these models, nonindependence of errors due to temporal autocorrelation was accounted for by the addition of a first-order autoregressive term (corAR1). Models with more than 2 levels were fitted with different intercepts to extract all comparative p-values. Due to insufficient computing power, the flight bout data, which exhibited only weak serial autocorrelation, were analysed without the corAR1 term. For the same reason, a number of com- 
parisons were carried out by means of paired and unpaired $t$-tests, which are conservative and therefore unlikely to result in Type I errors. Given the large number of comparisons, the threshold for statistical significance was taken to be $\mathrm{p}<0.01$. Observed means are reported with $\pm \mathrm{SD}$, parameter estimates are reported with \pm SE in tables and with $\pm 95 \% \mathrm{CI}$ in figures. The geometric mean (model estimates) may be a better representative of flight bout duration (where a few long bouts can skew the distribution), but the arithmetic observed mean is given in the tables to facilitate comparisons with previous studies.

\section{RESULTS \\ Comparison between commuting and resident behaviour}

Overall distributions for each species are indicated in Fig. 1. Some, but not all, individuals of each of the 4 species carried out some rapid commuting during part of the nonbreeding period. Six wandering albatrosses carried out 1 global circumnavigation, and one other made 2 such navigations. The remaining 11 birds made return commutes between one or more sectors in
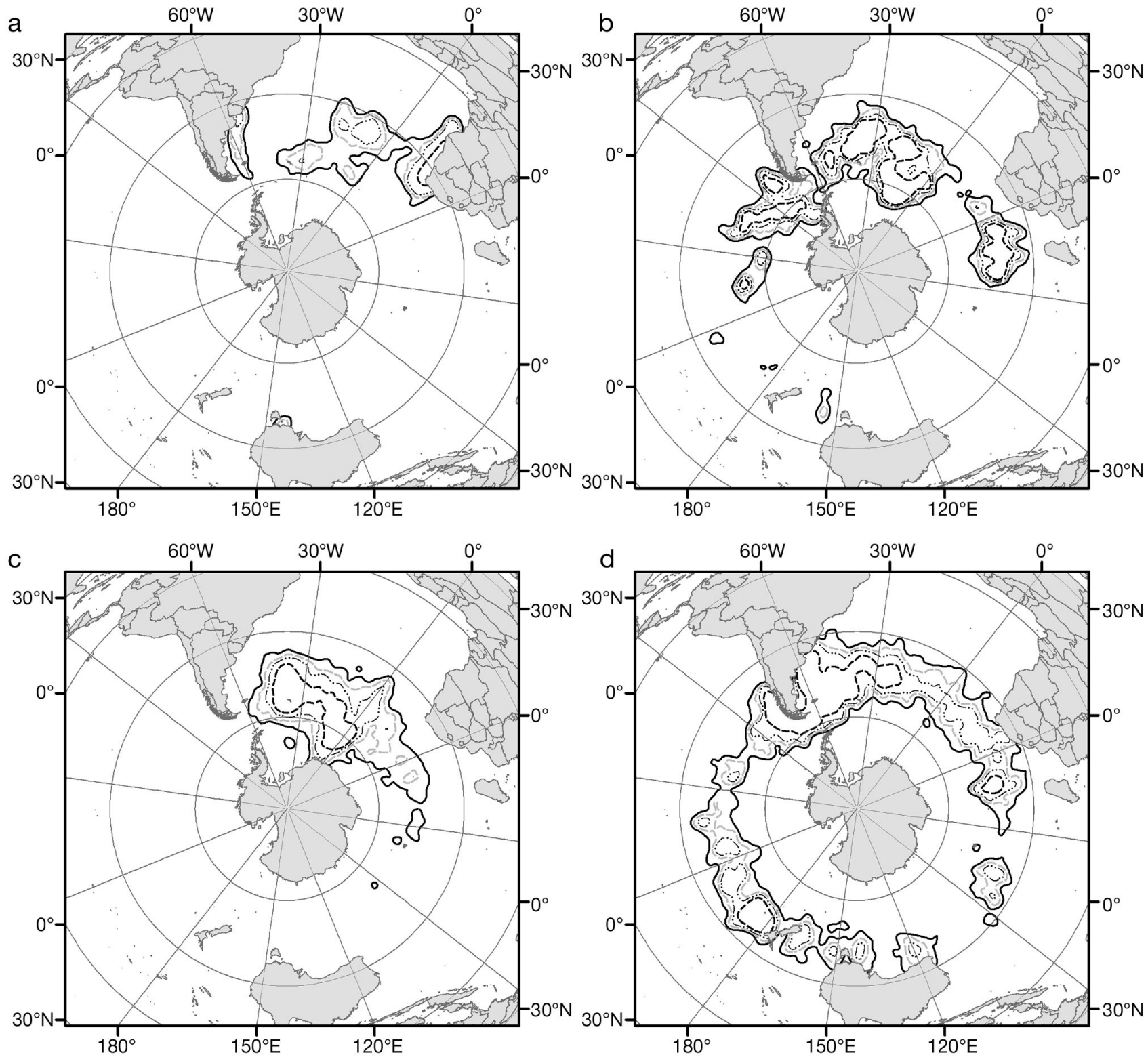

Fig. 1. Density distributions of (a) black-browed albatrosses ( $\mathrm{n}=25$ birds in 2002), (b) grey-headed albatrosses ( $\mathrm{n}=3$ birds in 2003 and $n=5$ birds in 2006), (c) light-mantled albatrosses ( $\mathrm{n}=1$ bird in 2003 and $n=10$ birds in 2004$)$ and (d) wandering albatrosses ( $\mathrm{n}=18$ birds in 2003) tracked during the nonbreeding period using geolocators. The maps show the 50\% (- -), $70 \%$ ( -.. ..), $80 \%(---)$ and $90 \%$ (-) density contours of the total distribution (British Antarctic Survey unpubl. data) 
the Pacific, Atlantic and Indian oceans. Seven greyheaded albatrosses used multiple sectors between the southwestern Pacific and western Indian oceans, one remained the entire winter in the south Atlantic Ocean, and none completed a circumnavigation (Fig. 1). Except for 1 bird that wintered off Australia and another off Argentina, all black-browed albatrosses commuted to the Benguela Upwelling off southwestern Africa ( $\mathrm{n}=23$ ) and later, for variable durations, westwards back into the south Atlantic Ocean (Fig. 1). Two light-mantled albatrosses commuted completely around the Southern Ocean, whereas the other 9 birds remained resident within a broad region from the South Atlantic to the southwestern Indian Ocean (Fig. 1).

In all species, the average proportion of time spent on the water during daylight was significantly less when commuting than when resident (commuting values were 35 to $59 \%$ of those when resident). The average proportion of time spent on the water during the night was also reduced, but not to the same extent (commuting values were 67 to $99 \%$ of those during resident phases) (Table 1). When commuting, black-browed and wandering albatrosses significantly increased flight effort (less time spent on the water plus longer flight bouts), during both daylight and darkness. Wandering albatrosses showed an equal distribution of time spent on the water be- tween daylight and darkness, whereas black-browed albatrosses spent overall a greater proportion of their total daily time on the water during darkness. This latter trend was shared by the smaller albatrosses, in particular the grey-headed albatross, which when commuting did not increase flight effort at night. There was no difference in the illuminated proportion of the moon's visible disc between the 2 movement phases for any species (paired $t$-tests: black-browed albatross: $t_{23}=0.12, \mathrm{p}=0.903$; greyheaded albatross: $t_{6}=1.34, \mathrm{p}=0.228$; wandering albatross: $t_{14}=0.90, \mathrm{p}=0.383$ ). This implies that birds did not take advantage of moonlit nights to commute. Maximum observed flight bout durations were $15.9,12.9,17.8$ and $17.6 \mathrm{~h}$ for black-browed, grey-headed, light-mantled and wandering albatrosses, respectively. For black-browed and lightmantled albatrosses these flight bouts occurred during commuting phases, rather than resident phases.

All individuals of all species were classified as resident for the majority of the nonbreeding period (means and ranges, respectively, of $92 \%$ and 64 to $100 \%, 91 \%$ and 75 to $96 \%, 94 \%$ and 90 to $100 \%$, and $96 \%$ and 75 to $100 \%$ for wandering, black-browed, grey-headed and light-mantled albatrosses, respectively). Therefore, all further comparisons excluded data from commuting phases.

Table 1. Activity patterns (observed mean $\pm \mathrm{SD}$ ) and test statistics $\left(t_{\mathrm{df}}\right.$ and p-values) for comparisons of the commuting and resident phases of the nonbreeding period of black-browed, grey-headed, light-mantled and wandering albatrosses. Note that only birds with one or more commuting phases are included and the test statistics for light-mantled albatross are not given because of the limited sample size. Mean values for the commuting phases that are significantly different from the resident phases are indicated $\left({ }^{* *} \mathrm{p}<0.001,{ }^{*} \mathrm{p} \leq 0.01\right.$; for $\mathrm{p}>0.01, \mathrm{p}$-values are given). $\mathrm{n}$ : number of birds

\begin{tabular}{|c|c|c|c|c|c|}
\hline & $\begin{array}{l}\text { Percent } \\
\text { darkness } \\
\text { on water }\end{array}$ & $\begin{array}{l}\text { Percent } \\
\text { daylight } \\
\text { on water }\end{array}$ & $\begin{array}{c}\text { Percent on } \\
\text { water by } \\
\text { darkness }\end{array}$ & $\begin{array}{l}\text { Flight bout in } \\
\text { duration } \\
\text { darkness (min) }\end{array}$ & $\begin{array}{c}\text { Flight bout } \\
\text { duration in } \\
\text { daylight (min) }\end{array}$ \\
\hline \multicolumn{6}{|c|}{ Black-browed albatross $(n=25)$} \\
\hline Commuting & $60.1 \pm 7.8$ & $17.9 \pm 5.1$ & $76.8 \pm 6.1$ & $109.8 \pm 20.6$ & $100.9 \pm 12.3$ \\
\hline Resident & $83.6 \pm 5.6$ & $50.8 \pm 6.9$ & $65.2 \pm 3.5$ & $78.6 \pm 8.7$ & $63.7 \pm 6.5$ \\
\hline$t_{24}$ & 8.86 & 15.37 & 8.83 & 8.86 & 15.37 \\
\hline $\mathrm{p}$ & ** & ${ }^{* *}$ & ${ }^{* *}$ & ** & ${ }^{* *}$ \\
\hline \multicolumn{6}{|c|}{ Grey-headed albatross $(n=7)$} \\
\hline Commuting & $72.9 \pm 10.3$ & $11.3 \pm 5.0$ & $82.8 \pm 10.6$ & $86.2 \pm 13.9$ & $97.7 \pm 10.2$ \\
\hline Resident & $73.6 \pm 5.8$ & $32.0 \pm 5.6$ & $70.5 \pm 4.3$ & $73.0 \pm 14.2$ & $68.7 \pm 6.9$ \\
\hline$t_{6}$ & 0.09 & 6.83 & 2.90 & 1.66 & 5.31 \\
\hline $\mathrm{p}$ & 0.931 & ${ }^{* *}$ & 0.027 & 0.148 & ${ }^{*}$ \\
\hline \multicolumn{6}{|c|}{ Light-mantled albatross $(n=2)$} \\
\hline Commuting & $44.1 \pm 26.2$ & $24.6 \pm 2.6$ & $64.3 \pm 21.3$ & $89.6 \pm 4.5$ & $73.6 \pm 4.5$ \\
\hline Resident & $65.4 \pm 1.7$ & $43.5 \pm 5.0$ & $55.0 \pm 6.8$ & $74.2 \pm 10.5$ & $81.0 \pm 8.1$ \\
\hline \multicolumn{6}{|c|}{ Wandering albatross $(n=15)$} \\
\hline Commuting & $58.6 \pm 13.3$ & $34.2 \pm 12.6$ & $54.5 \pm 12.7$ & $120.6 \pm 18.5$ & $114.4 \pm 18.4$ \\
\hline Resident & $78.5 \pm 4.5$ & $57.8 \pm 7.4$ & $54.2 \pm 4.7$ & $86.2 \pm 11.1$ & $82.9 \pm 11.1$ \\
\hline$t_{14}$ & 6.30 & 9.94 & 0.121 & 10.34 & 6.97 \\
\hline $\mathrm{p}$ & $* *$ & $* *$ & 0.905 & ${ }^{* *}$ & ${ }^{* *}$ \\
\hline
\end{tabular}




\section{Sex differences in behaviour}

For black-browed and wandering albatrosses, there were no significant differences in the proportions of time spent on the water by males compared with females during the nonbreeding period (summarised in Table 2). Males tended to engage in longer flight bouts, but the difference was only close to our significance threshold of $\mathrm{p}<0.01$ (see 'Materials and methods') in black-browed albatrosses at night $\left(t_{5904,23}=2.61, \mathrm{p}=0.016\right)$. The proportion of darkness experienced in each $24 \mathrm{~h}$ period by females was significantly less than that for male black-browed albatrosses (means of $50.6 \pm 0.6 \%$ and $51.8 \pm 1.2 \%$, respectively; $t$-test: $t_{23}=3.25, \mathrm{p}=0.004$ ), indicating that on average males spent the nonbreeding period further south. There was no difference between sexes in the proportion of darkness experienced in each $24 \mathrm{~h}$ period in wandering albatrosses (females: $46.3 \pm$ $1.3 \%$, males: $45.9 \pm 3.1 \%, t_{16}=0.36, p=0.725$ ). As sex effects were found to be slight, data for males and females were pooled for all subsequent analyses.

\section{Species differences in behaviour}

There were significant differences among species in all activity measures during resident phases of the nonbreeding period (Fig. 2). All 4 species spent a greater proportion of time on the water during darkness than in daylight (Fig. 2a). At night, black-browed albatrosses spent the most time and light-mantled albatrosses the least time on the water, whereas during daylight, wandering albatrosses spent the most time and grey-headed albatrosses the least time on the water. Overall, wandering and light-mantled albatrosses distributed time on the water more or less evenly between daylight and darkness, whereas grey-headed and black-browed albatrosses spent more of their time on the water in darkness (Fig. 2b). This may reflect the longer winter nights during the nonbreeding period of the Thalassarche spp. Mean flight bout durations were longest in wandering albatrosses during both darkness and daylight (Fig. 2c). Black-browed albatross flight bouts were far shorter during daylight than darkness.

\section{Individual, intra-specific and annual variation}

There was consistent variation among individuals within species in all 5 activity measures (1-way ANOVA: black-browed albatross: $F_{24,3926-19110}=2.78-17.29$, all $\mathrm{p}<$ 0.001 ; grey-headed albatross: $F_{7,1832-11566}=6.29-18.93$, all $\mathrm{p}<0.001$; light-mantled albatross: $F_{10,2780-14718}=$ 3.70-43.67, all $\mathrm{p}<0.001$; wandering albatross: $F_{17,5615-20116}=7.18-48.21$, all $\left.\mathrm{p}<0.001\right)$. This implies that, while within species there is a reasonably wide spectrum of foraging (activity) strategies, particular individuals are relatively fixed in their behaviour.

Activity patterns of 24 black-browed albatrosses were compared in 2 consecutive nonbreeding periods (austral winter 2002 and 2003). Although diurnal behaviour was consistent across years, birds in 2003 spent significantly less time on the water at night (paired $t$-test: $t_{23}=6.22, \mathrm{p}<0.001$ ) and less of their overall time on the water during darkness (paired $t$ test: $t_{23}=4.61, \mathrm{p}<0.001$; Fig. $\left.3 \mathrm{a}, \mathrm{c}\right)$. Although the observed means followed the same relative pattern of species activity, using data from 2003 instead of 2002 for black-browed albatrosses altered some parameter estimates (Table 3).

Table 2. Activity patterns (observed mean $\pm \mathrm{SD})$, with parameter estimates $( \pm \mathrm{SE}$, estimates are relative to females) and test statistics ( $t$ - and p-values) from a mixed effect generalised linear model of sex effects for black-browed and wandering albatrosses during the nonbreeding period. $\mathrm{n}$ : number of birds

\begin{tabular}{|c|c|c|c|c|c|c|}
\hline & $\begin{array}{c}\text { Female mean } \\
\pm \mathrm{SD}\end{array}$ & $\begin{array}{c}\text { Male mean } \\
\pm \mathrm{SD}\end{array}$ & $\begin{array}{c}\text { Parameter } \\
\text { estimate } \pm \mathrm{SE}\end{array}$ & df & $t$ & $\mathrm{p}$ \\
\hline Black-browed albatross & $\mathrm{n}=9$ & $\mathrm{n}=16$ & & & & \\
\hline$\%$ darkness on water & $84.6 \pm 5.1$ & $83.0 \pm 6.0$ & $-0.11 \pm 0.17$ & 3926,23 & 0.64 & 0.526 \\
\hline \% daylight on water & $49.3 \pm 7.7$ & $51.6 \pm 6.6$ & $0.08 \pm 0.11$ & 3926,23 & 0.75 & 0.461 \\
\hline$\%$ on water by darkness & $65.9 \pm 3.5$ & $64.8 \pm 3.5$ & $-0.05 \pm 0.06$ & 3926,23 & 0.76 & 0.458 \\
\hline \multicolumn{7}{|l|}{ Flight bout duration (min) } \\
\hline Darkness & $73.4 \pm 4.3$ & $81.4 \pm 9.4$ & $0.03 \pm 0.01$ & 5904,23 & 2.61 & 0.016 \\
\hline Daylight & $61.2 \pm 5.3$ & $65.1 \pm 6.8$ & $0.01 \pm 0.01$ & 19110,23 & 0.95 & 0.351 \\
\hline Wandering albatross & $\mathrm{n}=9$ & $\mathrm{n}=9$ & & & & \\
\hline$\%$ darkness on water & $77.3 \pm 4.1$ & $79.7 \pm 5.0$ & $0.03 \pm 0.16$ & 5643,16 & 0.19 & 0.852 \\
\hline \% daylight on water & $57.1 \pm 4.8$ & $58.6 \pm 10.0$ & $0.21 \pm 0.19$ & 5640,16 & 1.15 & 0.267 \\
\hline$\%$ on water by darkness & $54.8 \pm 3.9$ & $53.5 \pm 5.8$ & $-0.09 \pm 0.09$ & 5615,16 & 0.98 & 0.343 \\
\hline \multicolumn{7}{|l|}{ Flight bout duration (min) } \\
\hline Darkness & $81.0 \pm 8.4$ & $92.2 \pm 11.2$ & $0.03 \pm 0.01$ & 9130,16 & 2.23 & 0.040 \\
\hline Daylight & $77.9 \pm 7.5$ & $88.6 \pm 12.3$ & $0.03 \pm 0.02$ & 20116,16 & 1.92 & 0.073 \\
\hline
\end{tabular}



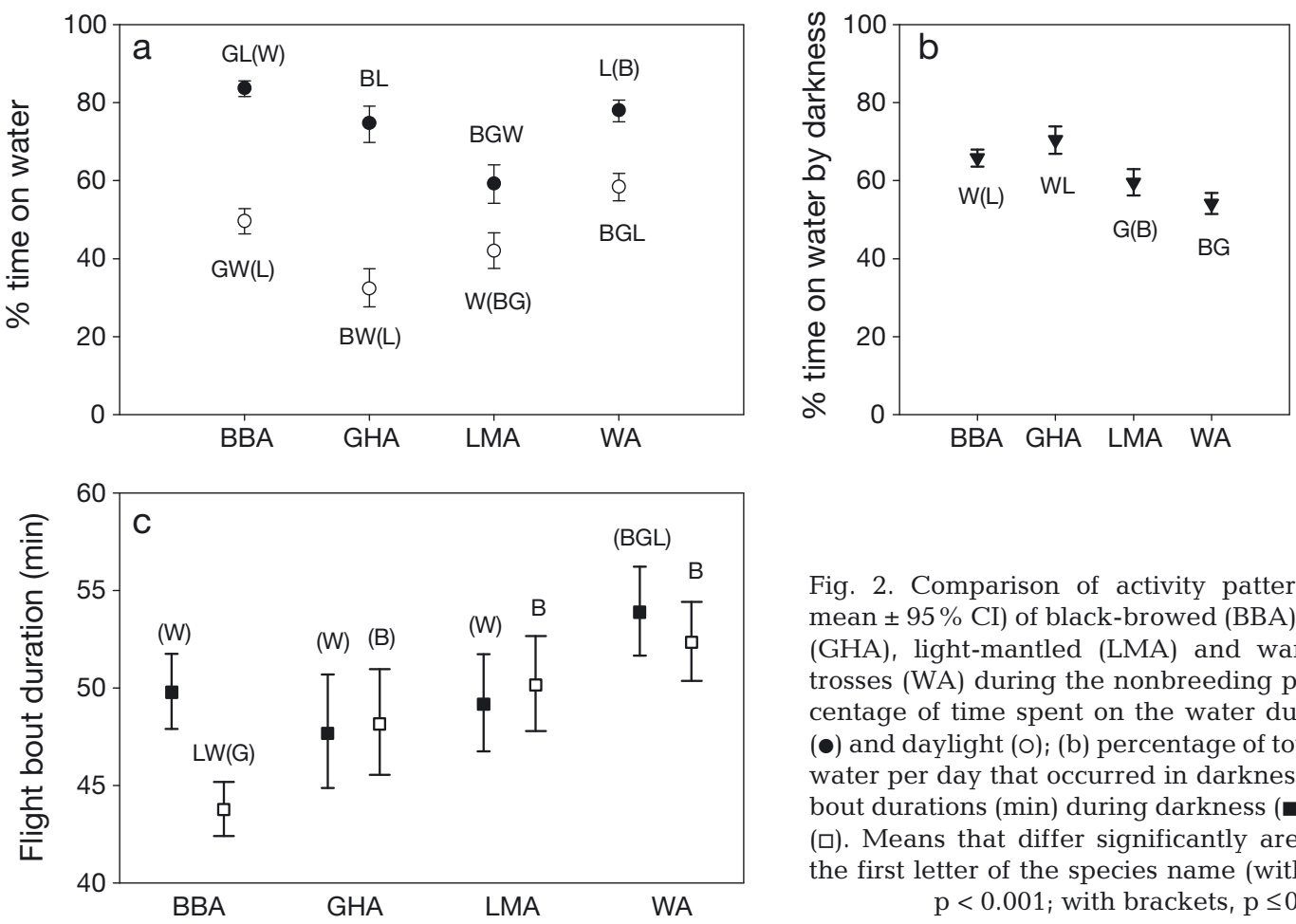

Fig. 2. Comparison of activity patterns (estimated mean $\pm 95 \% \mathrm{CI}$ ) of black-browed (BBA), grey-headed (GHA), light-mantled (LMA) and wandering albatrosses (WA) during the nonbreeding period. (a) Percentage of time spent on the water during darkness (•) and daylight (O); (b) percentage of total time on the water per day that occurred in darkness $(\mathbf{v}) ;($ c) flight bout durations (min) during darkness ( $\mathbf{\square})$ and daylight (). Means that differ significantly are indicated by the first letter of the species name (without brackets, $\mathrm{p}<0.001$; with brackets, $\mathrm{p} \leq 0.01)$

\section{Comparison between the nonbreeding and breeding periods}

All 4 species spent more time on the water during daylight in the nonbreeding period than when at sea during any stage of the breeding season (Fig. 4) with one exception: grey-headed albatrosses during the incubation period (Fig. 4b). In comparison, the proportion of time spent on the water during darkness during the nonbreeding period was similar to that in the breeding season, except in Thalassarche spp. during post-brood chick-rearing (Fig. 4a,b). However, this pattern was inconsistent: nonbreeding black- browed albatrosses spent more time and greyheaded albatrosses spent less time on the water compared with that during post-brood. For grey-headed albatrosses during incubation and brooding, the proportions of time on the water that occurred during darkness were less, and for wandering albatrosses during brood and post-brood the proportions were greater than in nonbreeding birds (Fig. 4b,d). In wandering albatrosses, these differences probably reflect longer winter nights during the later breeding stages, and in grey-headed albatrosses, the differences may relate to shorter summer nights midbreeding.
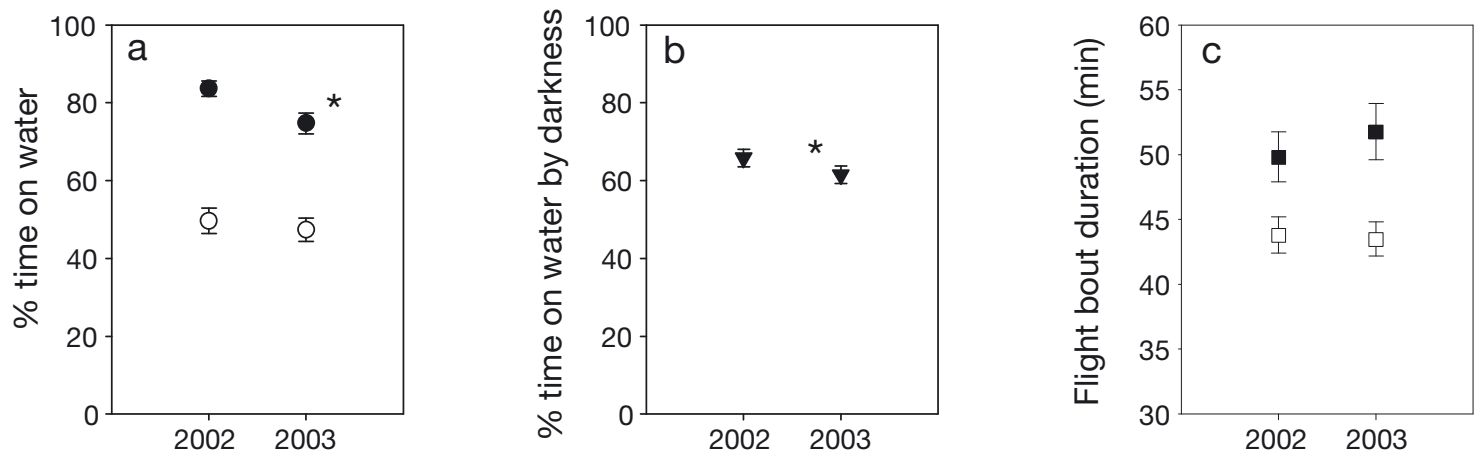

Fig. 3. Activity patterns (observed mean $\pm \mathrm{SD}$ ) of 24 black-browed albatrosses tracked in 2 consecutive nonbreeding periods (2002 and 2003). (a) Percentage of time spent on the water during darkness (•) and daylight (O); (b) percentage of total time on

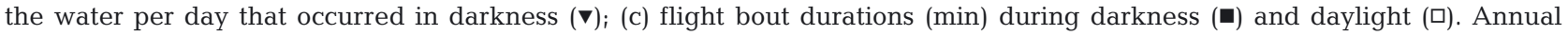
differences $(\mathrm{p}<0.001)$ are indicated by asterisk $(*)$ 


\section{DISCUSSION}

Although most pelagic seabirds spend the majority of the nonbreeding period at sea, this is one of only a few studies of at-sea activity patterns during this stage of their life cycle (Grémillet et al. 2000, Phillips et al. 2007a, Catry et al. 2009, Guilford et al. 2009) and the first to compare members of all Southern Ocean genera of albatross.

\section{Species activity patterns during the nonbreeding period}

The pattern of inter-specific variation in activity patterns from the resident phases of the nonbreeding period mirrored results from studies conducted during the breeding season. Nonbreeding wandering albatrosses exhibited longer flight bouts than did the smaller albatrosses, indicative of a strategy of wideranging searching in oceanic waters for highly dis- persed prey (Weimerskirch et al. 1997), and they also spent the greatest proportion of daylight on the water $(59 \%)$. This may be related to the high energetic costs of landing and takeoff (Weimerskirch et al. 2000), such that wandering albatrosses will not land unless prey capture is more or less assured, or to allow the consumption of larger prey items that require longer handling times than those of the smaller albatross species (Weimerskirch et al. 1997). In comparison, both blackbrowed and grey-headed albatrosses engaged in short flight bouts during daylight, indicative of arearestricted searching within patches of high prey density, in which prey capture may require active pursuit by plunging and diving within competitive feeding flocks (Harper 1987, Prince et al. 1994, Huin \& Prince 1997, Weimerskirch et al. 1997, Silverman \& Veit 2001).

At night black-browed albatrosses switched to longer searching flights to potentially target different prey species (e.g. switching to squid and other buoyant organisms obtained by scavenging). These albatrosses

Table 3. Model estimates (mean \pm SE) and test statistics ( $t$ - and p-values) for grey-headed (GHA), light-mantled (LMA) and wandering albatross (WA) relative to black-browed albatross (BBA) data from 2 consecutive years (2002 and 2003). Annual differences in individual activity patterns found for black-browed albatross altered the species comparison mixed-effects model output and in some cases significance (bold), although the observed means followed the same pattern of species activity. Significant species differences with respect to black-browed albatrosses are indicated $\left({ }^{* *} p<0.001,{ }^{*} p \leq 0.01\right.$; for $p>0.01$, $\mathrm{p}$-values are given)

\begin{tabular}{|c|c|c|c|c|c|c|c|c|}
\hline & \multicolumn{4}{|c|}{ Species comparison with BBA 2002 data } & \multicolumn{4}{|c|}{ Species comparison with BBA 2003 data } \\
\hline & $\begin{array}{c}\text { Model estimate } \\
\pm \mathrm{SE}\end{array}$ & df & $t$ & $\mathrm{p}$ & $\begin{array}{c}\text { Model estimate } \\
\pm \text { SE }\end{array}$ & df & $t$ & $\mathrm{p}$ \\
\hline \multicolumn{9}{|c|}{$\%$ darkness on water } \\
\hline BBA & $1.63 \pm 0.07$ & 14213,58 & & & $1.08 \pm 0.07$ & 15093,57 & & \\
\hline GHA & $-0.55 \pm 0.14$ & & 3.84 & ** & $-0.00 \pm 0.14$ & & 0.03 & 0.980 \\
\hline LMA & $-1.26 \pm 0.13$ & & 9.96 & ** & $-0.71 \pm 0.12$ & & 5.78 & ** \\
\hline WA & $-0.37 \pm 0.11$ & & 3.33 & * & $0.18 \pm 0.11$ & & 1.73 & 0.090 \\
\hline \multicolumn{9}{|c|}{$\%$ daylight on water } \\
\hline BBA & $-0.02 \pm 0.07$ & 14207,58 & & & $-0.11 \pm 0.06$ & 15140,57 & & \\
\hline GHA & $-0.73 \pm 0.13$ & & 5.60 & ${ }^{* *}$ & $-0.63 \pm 0.12$ & & 5.25 & $* *$ \\
\hline LMA & $-0.31 \pm 0.11$ & & 2.70 & * & $-0.22 \pm 0.11$ & & 2.05 & 0.045 \\
\hline WA & $0.36 \pm 0.10$ & & 3.65 & $* *$ & $0.44 \pm 0.09$ & & 4.91 & ${ }^{* *}$ \\
\hline \multicolumn{9}{|c|}{$\%$ on water by darkness } \\
\hline BBA & $0.65 \pm 0.05$ & 14153,58 & & & $0.47 \pm 0.05$ & 15029,57 & & \\
\hline GHA & $0.22 \pm 0.10$ & & 2.20 & 0.032 & $0.40 \pm 0.10$ & & 4.21 & $* * *$ \\
\hline LMA & $-0.27 \pm 0.09$ & & 3.10 & * & $-0.08 \pm 0.08$ & & 0.94 & 0.349 \\
\hline WA & $-0.49 \pm 0.07$ & & 6.68 & $* *$ & $-0.30 \pm 0.07$ & & 4.25 & ${ }^{* *}$ \\
\hline \multicolumn{9}{|c|}{ Flight bout duration in darkness (min) } \\
\hline BBA & $2.50 \pm 0.01$ & 29273,58 & & & $2.51 \pm 0.01$ & 33137,57 & & \\
\hline GHA & $-0.02 \pm 0.01$ & & 1.20 & 0.236 & $-0.03 \pm 0.01$ & & 2.01 & 0.490 \\
\hline LMA & $-0.00 \pm 0.01$ & & 0.39 & 0.700 & $-0.02 \pm 0.01$ & & 1.42 & 0.161 \\
\hline WA & $0.03 \pm 0.01$ & & 2.77 & $*$ & $0.01 \pm 0.01$ & & 1.29 & 0.202 \\
\hline \multicolumn{9}{|c|}{ Flight bout duration in daylight (min) } \\
\hline BBA & $2.45 \pm 0.01$ & 65510,58 & & & $2.44 \pm 0.01$ & 72629,57 & & \\
\hline GHA & $0.04 \pm 0.01$ & & 2.98 & * & $0.04 \pm 0.01$ & & 3.37 & * \\
\hline LMA & $0.05 \pm 0.01$ & & 4.72 & ${ }^{* * *}$ & $0.05 \pm 0.01$ & & 5.22 & ${ }^{* *}$ \\
\hline WA & $0.07 \pm 0.01$ & & 7.17 & ${ }^{* *}$ & $0.07 \pm 0.01$ & & 7.83 & ${ }^{* *}$ \\
\hline
\end{tabular}


a) Black-browed albatross (Nbp: Apr to Oct, Pbr: Jan to Mar)
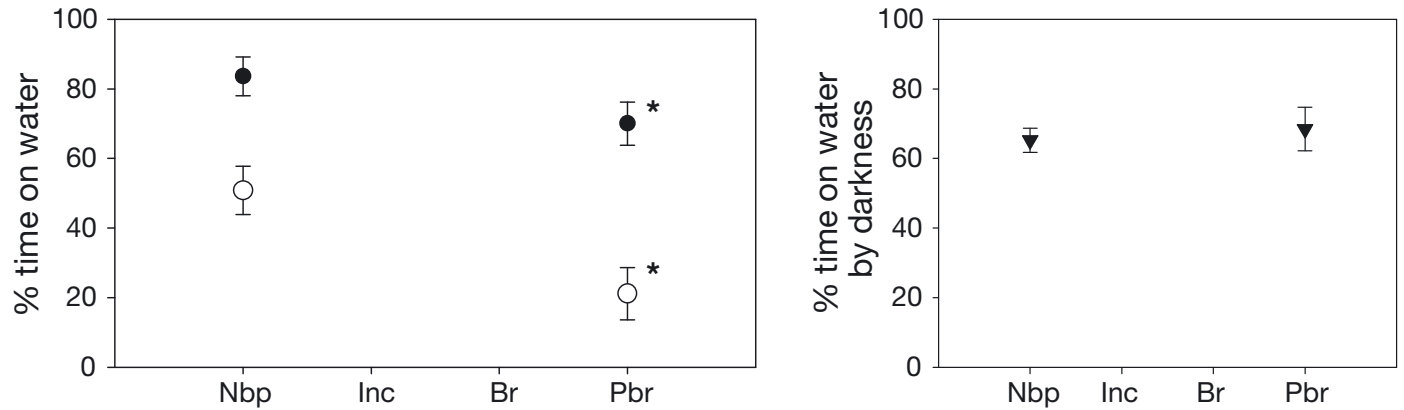

b) Grey-headed albatross (Nbp: Jan to Sep, Brp: Nov to Mar)
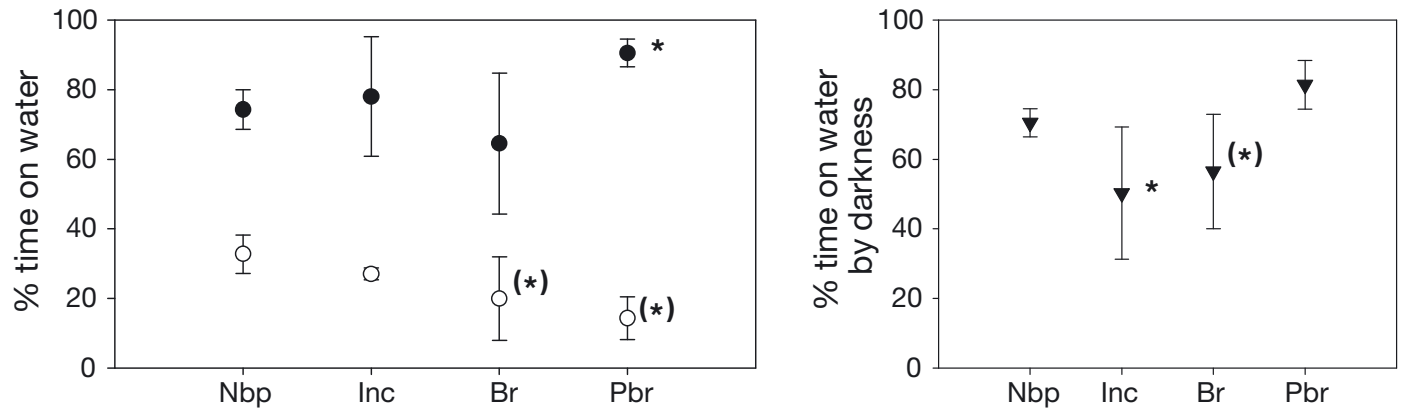

c) Light-mantled albatross (Nbp: Feb to Oct, Pbr: Jan to Feb)
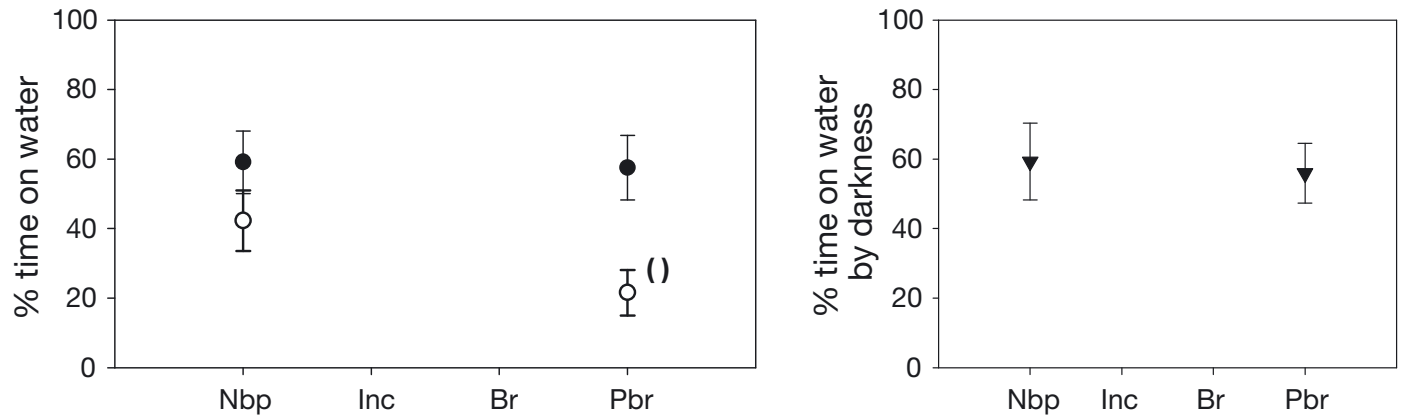

d) Wandering albatross (Nbp: Dec to Nov, Brp: Feb to Sep)
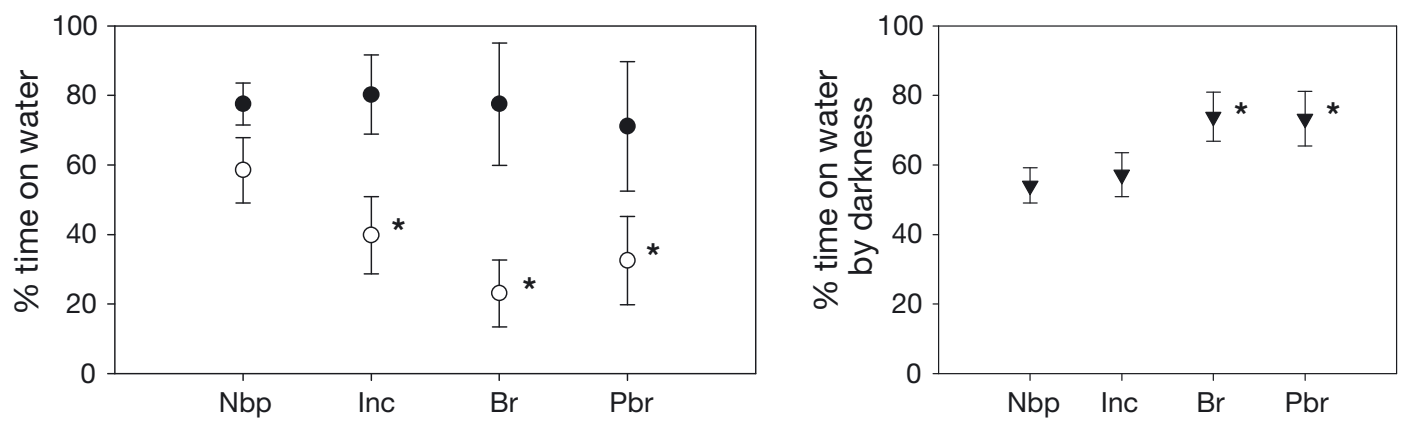

Fig. 4. Percentage of time spent on the water (mean \pm SD) during darkness $(\bullet)$ and daylight $(0)$, and percentage of total time on the water per day that occurred in darkness ( $\mathbf{v})$, by (a) black-browed, (b) grey-headed, (c) light-mantled and (d) wandering albatrosses during the nonbreeding period ( $\mathrm{Nbp}$ ) and incubating (Inc), brooding (Br) and post-brood (Pbr) stages. Mean values for the breeding stages that are significantly different from the nonbreeding period are indicated: $* p<0.001,(*) p \leq 0.01$; bracket-only symbol ( ) indicates borderline significance $(p=0.011)$. The breeding-period (Brp) data are taken from Phalan et al. (2007); there were no comparable data on flight bout duration 
may also adopt longer searching flights as pelagic prey such as krill become harder to locate because of reduced visibility despite the diel vertical migration of zooplankton and higher trophic organisms to the ocean surface at night (Phalan et al. 2007). Recent studies by Nevitt et al. $(2004,2008)$ have begun to elucidate the use of olfaction by foraging albatrosses; black-browed and wandering albatrosses are responsive to olfactory stimulants (i.e. those tested to date), whereas greyheaded and light-mantled albatrosses are not. Therefore, the differences in nocturnal activity evident in this study may arise because black-browed albatrosses increasingly rely upon olfaction when visual cues from prey and other birds diminish. For example, the longer flight bouts of black-browed albatrosses may occur as birds following a scent trail zigzag upwind to locate their prey (Nevitt et al. 2008). In wandering albatrosses, the lack of a significant diel difference probably reflects their consistent foraging strategy of long searching flights to locate sparsely distributed prey (predominantly squid) in oceanic waters (Weimerskirch et al. 2005). Furthermore, such unpredictable prey may be detected and tracked upwind using olfaction during both darkness and daylight (Nevitt et al. 2008).

Although the Thalassarche spp. shared similar diurnal activity patterns, grey-headed albatrosses spent a greater proportion of darkness on the water and probably use an opportunistic sit-and-wait strategy to capture bioluminescent prey such as squid and salps that migrate to the water's surface at night (Catry et al. 2004). Despite targeting productive upwelling zones, this foraging method captures few prey relative to that captured in active pursuit during daylight (Catry et al. 2004), which is presumably the preferred foraging method. This suggests that during darkness greyheaded albatrosses are limited by their olfactory and visual acuity. Certainly, within this suite of Southern Ocean species, the grey-headed albatross was least able (or willing) to increase flight time at night, whether in response to increased foraging demands, for example during chick-rearing, or to commute (see below). Light-mantled albatrosses, which are unresponsive to olfactory stimulants (Nevitt et al. 2004), presumably have superior nocturnal vision that enables them to forage in flight during darkness for a greater length of time than do the other species.

Light-mantled albatrosses were the most nocturnally active species, spending just $59 \%$ of the night on the water compared with 74,74 and $78 \%$ by grey-headed, black-browed and wandering albatrosses, respectively. This parallels the situation during the postbrood stage, when light-mantled albatrosses spend just $58 \%$ of the night on the water compared with 70 to $91 \%$ by the other albatross species (Phalan et al. 2007).
Past studies have considered whether light-mantled albatrosses feed on living or dead prey, and whether most captures are during daylight or darkness (Croxall \& Prince 1994, Phillips et al. 2005b). As nonbreeding light-mantled albatrosses maintain a high level of nocturnal activity even when freed of the central place constraint imposed by breeding, our study implies that flights undertaken at night are indicative of active searching for prey rather than commuting; it can be assumed the same is usually true during breeding. Nevertheless, given that nonbreeding birds of all species were most active during daylight, just as during the breeding period (Catry et al. 2004, Weimerskirch et al. 2005, Phalan et al. 2007), considerably more foraging can be assumed to take place during daylight than in darkness.

Nonbreeding albatrosses, no longer constrained to their colonies, are able to disperse widely. It seems reasonable to assume that the extent of available habitat increases and that inter-and intraspecific competition is less intense than during breeding. Therefore, the lack of change in relative behaviour from the breeding period, in particular for light-mantled albatrosses, for which it has been hypothesised they are competitively excluded by other albatrosses from local waters (see Phillips et al. 2005b), suggests that the activity patterns of each species reflect foraging niche specialisations that are maintained throughout the year. Moreover, the lack of significant change in foraging behaviour suggests they are consistent in their prey capture method, and, therefore, potentially in the type of prey caught. For most species, there is little information on diet during the nonbreeding period, with the exception of black-browed albatrosses that are known to follow fishing vessels in large numbers (Petersen et al. 2008). The view that nonbreeder activity patterns are not radically different from those of breeding birds might therefore be surprising, except that recent tracking data for black-browed albatrosses in the Benguela Upwelling found that many birds spent surprisingly little time in association with fisheries, and must have diets predominantly or entirely consisting of natural prey (Petersen et al. 2008).

\section{Comparison with breeding period activity patterns}

Fundamental to the nonbreeding period is the lack of reproductive effort and central place constraint, allowing individuals to minimise costs whilst investing in future survival. As free-ranging foragers, nonbreeding albatrosses can minimise energy expenditure relative to prey intake by moving directly between areas of profitable prey capture and by resting on the water between foraging bouts. All 4 albatross species spent 
more time resting on the water surface during daylight in the nonbreeding period than at any breeding stage: 51, 33, 42 and $59 \%$ for black-browed, grey-headed, light-mantled and wandering albatrosses, respectively, compared with maximum values of 21, 27, 22 and $40 \%$ during breeding (Phalan et al. 2007). As most prey are caught during daylight (Weimerskirch et al. 1997, 2005, Catry et al. 2004), this suggests nonbreeding birds readily meet their energy demands. Due to differing methodologies a direct comparison could not be made with the previous activity study of nonbreeding black-browed albatrosses by Grémillet et al. (2000). Nevertheless, a similar general pattern was found, with birds spending overall more time on the water during the nonbreeding period (63\%) than during incubation (48\%) (Grémillet et al. 2000). In general, activity patterns during the nonbreeding period were most similar to those recorded during incubation, and least similar to the guard period when adults take turns brooding the chick and central place constraints are strongest. This corroborates the findings of Phalan et al. (2007) that showed energetic constraints play a decisive role in determining activity patterns.

Birds may also spend greater proportions of time on the water surface during moult to reduce time and therefore energy spent in flight, which is a costly activity, and/or because flight itself is impaired by reduced efficiency or control, with the latter potentially increasing risk of injury (Bridge 2006). Despite the lack of comparable mean flight bout data for the breeding period, it may be surmised from the rapid commutes, and in some cases circumnavigations made by individuals of all species, that nonbreeding birds were not constrained in their flight capabilities, or at least not for prolonged periods. Furthermore, maximum flight bout durations were similar to those recorded during the breeding period (see below). This may be expected, as albatrosses moult their primaries gradually and continuously throughout the nonbreeding period, and birds are able to control the spread of their wings to minimise gaps between overlapping feathers (Bridge 2006). Therefore, the effects of moult are likely to be minimal, in comparison with the lack of reproductive constraints, in determining nonbreeding activity patterns

\section{Commuting phases}

During the nonbreeding period, some individuals of all species made rapid movements that involved, as might be expected, a much greater proportion of time spent in flight, on average, than during resident phases. The increases in flight effort were much more apparent during daylight compared with darkness, when the proportions of time spent on the water were, respectively, 35 to $62 \%$ versus 67 to $99 \%$ of those during resident periods. The increases in flight effort were most pronounced in black-browed and grey-headed albatrosses during daylight, and least marked $(<1 \%$ increase) in grey-headed albatrosses at night. This suggests that, despite travelling over open seascapes, most albatrosses prefer to move at speed over long distances when ambient light levels are high. It is possible that there is always a portion of the night when it is difficult for albatrosses to navigate, particularly during commutes that do not coincide with moonlit nights, and/or that they cannot sustain long-distance flight over consecutive days without incorporating substantial periods of rest.

Differences in eye structure may improve nocturnal vision and thereby potentially allow commuting at lower light levels; this could, for example, explain why the light-mantled albatross is the most nocturnally active of the species in our study. However, differences in vision do not always have a direct effect upon behaviour; Laysan albatrosses Phoebastria immutabilis have better nocturnal vision, but do not forage during darkness to a greater extent than do black-footed albatrosses P. nigripes (Fernández \& Anderson 2000). Nor are there significant differences in eye structure between black-browed and grey-headed albatrosses (Martin 1998), which would suggest there is a behavioural rather than an anatomical basis for the differences in activity pattern we observed between these species.

For all species, the mean flight bouts during commuting were longer than those recorded during periods of residence, indicating that birds rest and/or feed less regularly when commuting. Intuitively, we would expect that commuting is more likely to occur when birds have to cross less productive areas of the ocean. For example, the majority of black-browed albatrosses from South Georgia migrate between 4 distinct areas of the Atlantic Ocean, with each movement occurring as a rapid commute (Phillips et al. 2005a, our present study). This strategy presumably improves efficiency by minimising the time spent in areas of lower prey availability, and therefore during commuting phases birds will tend to maximise time in flight. In this context, it is noteworthy that the maximum observed flight bout durations of nonbreeding wandering, greyheaded and black-browed albatrosses of 18, 13 and $16 \mathrm{~h}$, respectively, were remarkably similar to those reported in previous studies during the breeding season (Weimerskirch \& Guionnet 2002, Edwards et al. 2007). The absence of a long tail to the frequency distribution of flight durations (i.e. no extremely long flights), supports a recent analysis concluding that wandering albatrosses do not exhibit Lévy flight 
search patterns, and therefore that prey are not necessarily fractally distributed on the sea surface (Edwards et al. 2007). Similarly, it implies that maximum flight duration is limited by the requirement to rest or forage, or the inability to navigate effectively during at least part of the night, rather than by the spatial distribution of prey.

\section{Intrinsic and extrinsic influences}

Sex differences in activity patterns have not been found for albatrosses during either the breeding (Phalan et al. 2007) or the nonbreeding periods (the present study), despite some latitudinal segregation. This implies that although they may feed in different water masses, the sexes are consistent in the types of prey targeted and use similar foraging methods. This foraging niche specialisation during the nonbreeding period has recently been demonstrated through stable isotope analysis, whereby dimorphic sexes had similar nitrogen isotope ratios, indicative of trophic level, despite subtle differences in carbon isotope ratios, indicative of water mass (Phillips et al. 2009). As segregation still occurs during the nonbreeding period, when competition is lowest (Weimerskirch \& Wilson 2000, Phillips et al. 2008), it may be inferred that one sex is not excluded by the other, but selects wind regimes to which their morphologies are best suited.

Studies of albatross dispersal and migration have shown that individuals are highly consistent in their nonbreeding distribution, initiation of return migration and arrival at the colony (Phillips et al. 2008). However, date of departure, and thereby duration of the nonbreeding period, is dependent upon whether the individual was successful and when it failed in that season, which may be highly variable from year to year. Between 2 consecutive years (2002 and 2003), 24 black-browed albatrosses were consistent in individual behaviour patterns during daylight, but not during darkness; in 2003, birds spent a smaller proportion of time on the water $(74 \%)$ and engaged in longer bouts of flight (84 min) relative to 2002 (84\% and $79 \mathrm{~min}$, respectively). This suggests that, overall, there was a difference in the type or distribution of nocturnal prey available, possibly due to differences in the duration and/or timing of use of various foraging areas. As a higher proportion of birds failed to breed, the blackbrowed albatrosses left the colony on average 2 mo earlier in 2003 than in 2002, and although they visited the same ocean sectors, they spent more time in the central South Atlantic Ocean and less in the Benguela Upwelling in 2003 (27 and 59\%, respectively) compared with 2002 (18 and $71 \%$, respectively). However, differences in activity may not be attributable to ocean sector per se. These are heterogeneous environments and differences in prey may occur that are associated with changes in atmospheric and oceanographic circulations, sea surface temperatures and the position and strength of upwellings, gyres and oceanic fronts, which in turn alter foraging patterns between years (e.g. Xavier et al. 2003, Pinaud et al. 2005). Indeed, further work could investigate the implications of individual variation in activity patterns during the nonbreeding period for breeding probability, timing and success (e.g. Daunt et al. 2006).

Acknowledgements. We are very grateful to the many field workers at Bird Island for their help with deploying and retrieving data loggers, and to J. P. Croxall for supporting the albatross research at Bird Island. This research represents a contribution to the BAS Ecosystems Programme. N. Ratcliffe and R. Robinson gave advice on the statistical analysis and mixed models in R. We also thank 3 anonymous referees for their comments on an early version of the manuscript.

\section{LITERATURE CITED}

Afanasyev V (2004) A miniature daylight level and activity data recorder for tracking animals over long periods. Mem Natl Inst Polar Res 58(Spec Issue):227-233

Berthold P, Gwinner E, Sonnenschein E (eds) (2003) Avian migration. Springer-Verlag, Berlin

Bridge ES (2006) Influences of morphology and behavior on wing-molt strategies in seabirds. Mar Ornithol 34:7-19

Catry P, Phillips RA, Phalan B, Silk JRD, Croxall JP (2004) Foraging strategies of grey-headed albatrosses Thalassarche chrysostoma: integration of movements, activity and feeding events. Mar Ecol Prog Ser 280:261-273

Catry T, Ramos JA, Le Corre M, Phillips RA (2009) Movements, at-sea distribution and behaviour of a tropical pelagic seabird: the wedge-tailed shearwater in the western Indian Ocean. Mar Ecol Prog Ser 391:231-242

Clarke J, Kerry K, Fowler C, Lawless R, Eberhard S, Murphy R (2003) Post-fledging and winter migration of Adélie penguins Pygoscelis adeliae in the Mawson region of East Antarctica. Mar Ecol Prog Ser 248:267-278

Corkeron PJ, Connor RC (1999) Why do baleen whales migrate? Mar Mamm Sci 15:1228-1245

Croxall JP, Prince PA (1994) Dead or alive, night or day: How do albatrosses catch squid? Antarct Sci 6:155-162

> Croxall JP, Silk JRD, Phillips RA, Afanasyev V, Briggs DR (2005) Global circumnavigations: tracking year-round ranges of nonbreeding albatrosses. Science 307:249-250

Daunt F, Afanasyev V, Silk JRD, Wanless S (2006) Extrinsic and intrinsic determinants of winter foraging and breeding phenology in a temperate seabird. Behav Ecol Sociobiol 59:381-388

> Edwards AM, Phillips RA, Watkins NW, Freeman MP and others (2007) Revisiting Lévy flight search patterns of wandering albatrosses, bumblebees and deer. Nature 449: 1044-1048

Fernández P, Anderson DJ (2000) Nocturnal and diurnal foraging activity of Hawaiian albatrosses detected with a new immersion monitor. Condor 102:577-584

> Grémillet D, Wilson RP, Wanless S, Chater T (2000) Blackbrowed albatrosses, international fisheries and the Patagonian Shelf. Mar Ecol Prog Ser 195:269-280

Guilford T, Meade J, Willis J, Phillips RA and others (2009) 
Migration and stopover in a small pelagic seabird, the Manx shearwater Puffinus puffinus: insights from machine learning. Proc Biol Sci 276:1215-1223

Harper PC (1987) Feeding behaviour and other notes on twenty species of procellariiforms at sea. Notornis 34: 169-192

Huin N, Prince PA (1997) Diving behaviour of the greyheaded albatross. Antarct Sci 9:243-249

Kenney RD, Mayo CA, Winn HE (2001) Migration and foraging strategies at varying spatial scales in western North Atlantic right whales: a review of hypotheses. J Cetacean Res Manag 2(Spec Issue):251-260

Martin GR (1998) Eye structure and amphibious foraging in albatrosses. Proc Biol Sci 265:665-671

Nevitt G, Reid K, Trathan P (2004) Testing olfactory foraging strategies in an Antarctic seabird assemblage. J Exp Biol 207:3537-3544

Nevitt GA, Losekoot M, Weimerskirch H (2008) Evidence for olfactory search in wandering albatross, Diomedea exulans. Proc Natl Acad Sci USA 105:4576-4581

Petersen SL, Phillips RA, Ryan PG, Underhill LG (2008) Albatross overlap with fisheries in the Benguela Upwelling System: implications for conservation and management. Endang Species Res 5:117-127

Phalan B, Phillips RA, Silk JRD, Afanasyev V and others (2007) Foraging behaviour of four albatross species by night and day. Mar Ecol Prog Ser 340:271-286

Phillips RA, Xavier JC, Croxall JP (2003) Effects of satellite transmitters on albatrosses and petrels. Auk 120: 1082-1090

Phillips RA, Silk JRD, Phalan B, Catry P, Croxall JP (2004a) Seasonal sexual segregation in two Thalassarche albatross species: competitive exclusion, reproductive role specialisation or foraging niche divergence? Proc Biol Sci 271:1283-1291

Phillips RA, Silk JRD, Croxall JP, Afanasyev V, Briggs DR (2004b) Accuracy of geolocation estimates for flying seabirds. Mar Ecol Prog Ser 266:265-272

Phillips RA, Silk JRD, Croxall JP, Afanasyev V, Bennett VJ (2005a) Summer distribution and migration of nonbreeding albatrosses: individual consistencies and implications for conservation. Ecology 86:2386-2396

Phillips RA, Silk JRD, Croxall JP (2005b) Foraging and provisioning strategies of the light-mantled sooty albatross at South Georgia: competition and co-existence with sympatric pelagic predators. Mar Ecol Prog Ser 285:259-270

Phillips RA, Catry P, Silk JRD, Bearhop S, McGill R, Afanasyev V, Strange IJ (2007a) Movements, winter distribution and activity patterns of Falkland and brown skuas: insights from loggers and isotopes. Mar Ecol Prog Ser 345: 281-291

Phillips RA, Croxall JP, Silk JRD, Briggs DR (2008) Foraging ecology of albatrosses and petrels from South Georgia: two decades of insights from tracking technologies. Aquat Conserv 17(Suppl1 Mar Freshwat Ecosyst):S6-S21

Editorial responsibility: Yves Cherel,

Villiers-en-Bois, France
Phillips RA, Bearhop S, Mcgill RAR, Dawson DA (2009) Stable isotopes reveal individual variation in migration strategies and habitat preferences in a suite of seabirds during the nonbreeding period. Oecologia 160:795-806

> Pinaud D, Cherel Y, Weimerskirch H (2005) Effect of environmental variability on habitat selection, diet, provisioning behaviour and chick growth in yellow-nosed albatrosses. Mar Ecol Prog Ser 298:295-304

Pinheiro JC, Bates DM (2000) Mixed effects models in S and S-PLUS. Springer, New York

Prince PA, Rodwell S, Jones M, Rothery P (1993) Moult in black-browed and grey-headed albatrosses Diomedea melanophris and D. chrysostoma. Ibis 135:121-131

> Prince PA, Huin N, Weimerskirch H (1994) Diving depths of albatrosses. Antarct Sci 6:353-354

> Prince PA, Weimerskirch H, Huin N, Rodwell S (1997) Molt, maturation of plumage and ageing in the wandering albatross. Condor 99:58-72

R Development Core Team (2008) R: a language and environment for statistical computing. R Foundation for Statistical Computing, Vienna, www.R-project.org

Rasmussen K, Palacios DM, Calambokidis J, Saborío MT and others (2007) Southern Hemisphere humpback whales wintering off Central America: insights from water temperature into the longest mammalian migration. Mar Biol Lett 3:302-305

> Shaffer SA, Tremblay Y, Weimerskirch H, Scott D and others (2006) Migratory shearwaters integrate oceanic resources across the Pacific Ocean in an endless summer. Proc Natl Acad Sci USA 103:12799-12802

Silverman ED, Veit RR (2001) Associations among Antarctic seabirds in mixed species feeding flocks. Ibis 143:51-62

Venables WN, Ripley BD (2002) Modern applied statistics with S, 4th edn. Springer, New York

Weimerskirch H (1991) Sex-specific differences in molt strategy in relation to breeding in the wandering albatross. Condor 93:731-737

> Weimerskirch H, Guionnet T (2002) Comparative activity pattern during foraging of four albatross species. Ibis 144:40-50

- Weimerskirch H, Wilson RP (2000) Oceanic respite for wandering albatrosses. Nature 406:955-956

> Weimerskirch H, Wilson RP, Lys P (1997) Activity pattern of foraging in the wandering albatross: a marine predator with two modes of prey searching. Mar Ecol Prog Ser 151: $245-254$

Weimerskirch H, Guionnet T, Martin J, Shaffer SA, Costa DP (2000) Fast and fuel efficient? Optimal use of wind by flying albatrosses. Proc Biol Sci 267:1869-1874

> Weimerskirch H, Gault A, Cherel Y (2005) Prey distribution and patchiness: factors in foraging success and efficiency of wandering albatrosses. Ecology 86:2611-2622

Xavier JC, Croxall JP, Trathan PN, Wood AG (2003) Feeding strategies and diets of breeding grey-headed and wandering albatrosses at South Georgia. Mar Biol 143:221-232

Submitted: July 20, 2009; Accepted: February 8, 2010

Proofs received from author(s): April 24, 2010 